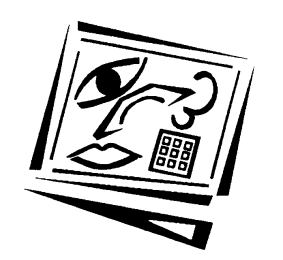

\title{
Transforming Vietnam's medical education through e-learning
}

\author{
Michael W. Churton \\ University of South Florida
}

\begin{abstract}
The costs for providing medical school education and services in Vietnam's universities continue to increase. Through a collaborative project between the Government of the Netherlands and Vietnam's Ministry of Health, a five year experimental program to develop in-country capacity and reduce the dependence upon a foreign medical service delivery model was initiated in 2007. A consortium of eight Vietnamese medical universities is participating in the project. The primary purpose is to design and strengthen the capacity of Vietnamese medical programs, personnel, and students in developing technical and pragmatic knowledge in several key medical and scientific categories that are currently directed by international consultants. The project intends to empower Vietnam's medical community to be selfreliant in the delivery of medical training and services to address the significant health needs of the country. To assist in the management and capacity building of the project across the eight medical universities, centres of excellence (COEs) have been proposed, encompassing five core constructs including health management, medical education, economic evaluation, medical research, and e-learning. This paper will address the design and development of two centres of excellence in e-learning.
\end{abstract}

\section{Introduction}

Vietnam's medical and health system requires an increased emphasis on primary care, prevention of disease and other health concerns. The Ministry of Health, having a traditional influence on health polices and university programs, is reforming gradually due to the increasing process of economic and fiscal decentralisation. All medical university programs in Vietnam require a national entrance examination. Approximately one in every 30 students who take the entrance examination is accepted. The medical curriculum is a six year program, discipline-based and teachercentred (Hoat, Nguyen \& Wright, 2008). After preparatory work including mathematics and physics, basic medical sciences (e.g. anatomy, biochemistry) are initiated in year two and onwards. Clinical theory begins in the third or fourth year, followed by or combined with clinical practice. Vietnam, however, continues to face significant challenges in the provision of medical and health services (Hoat \& Wright, 2008; Ministry of Health, 2007). Disparities exist in several key public health indicators reflected by region, income, and ethnicity (World Health Organization, 2010). In addition, the growing health disparities are compounded by an increased demand for trained medical personnel to meet world-class standards (Hoat et al., 2008).

\section{Need for intervention}

Vietnam's public health needs continue to be a priority not only for the government but also for universities and health care providers. The advancement of knowledge and information continues to increase, influencing medical strategies, intervention 
policies, educational opportunities, international linkages, and partnerships for shared services and resources. However, academic and instructional quality, integrity, and access remain keys to effectiveness and sustainability of these relationships (Churton, 2004). As universities consider the use of e-learning, a concern for quality control and support systems to ensure programmatic integrity requires concerted attention (Nair \& Finucane, 2003; Frohberg, Goth \& Schwabe, 2009). Universities must identify and apply appropriate curriculum design, course development, instructional support, and evaluation measures to ensure that their e-students and their e-instructors experience an effective transition to an e-learning/teaching environment (Churton, 2010).

Information and communication technologies (ICT) have enabled higher education institutions to offer a wide range of innovative approaches to personnel preparation and research (Churton, 2004). Vietnam's health care system faces continual challenges, due to economic and development changes, that have resulted in new patterns of how health services are provided (World Health Organization, 2010). Information and communication technology can and perhaps should play an influential role in medicine and health care including medical technology, information sharing, teaching methodologies and research. Internationally, research in medicine and related fields such as sociology and anthropology is producing new information concerning emerging diseases such as HIV, SARS and others. Information science and technology is required to bring this information to health care providers and practitioners in the field as well as to universities (Hoat et al., 2008). Traditional formats for sharing information especially in university programs are still useful, but often these formats cannot maintain currency nor present the most viable information to students. For medical education, ICT formats create new and innovative opportunities for students, but at the same time create challenges for instructors and universities. Information technology as a means to infuse information and to update university teaching and learning is critical for improving medical and health services.

A need continues, to integrate information technologies with existing instructional methods used in Vietnam's medical universities. To be effective, instructors require long-term training in order to transition from traditional methodologies and strategies to an e-learning environment and to increase curriculum and content offerings. The theoretical design is critical to ensure that content, assignments, and evaluation meet or exceed discipline standards (Scagnoli, Buki \& Johnson, 2009). As medical universities and their instructors move more towards student-centred learning, students will require an instructional transition as to how they receive information through an e-learning approach. In addition, the application of e-learning addresses the needs not only of urban universities but also the needs of programs serving rural health care providers as well (Wiesenberg \& Stacey, 2005).

\section{Theoretical construct and relevant literature}

The intended outcome, to achieve a systemic transformation of the traditional instructor-centred model, used predominantly in Vietnam's medical universities, to a learner-centered e-learning model, is a formidable task (Clark, 2002; Leung, 2002). Change within Vietnam's medical universities is at best, complicated, when considering the number of universities involved, traditional methodologies, fiscal limitations, as well the educational and philosophical backgrounds of instructors and administrators and the learning styles of students. Traditional instructor-centred teaching is yielding slowly to a more learner-centred approach that places self-learning 
and instructor-facilitated instruction at the foci. E-learning is the use of information and communications technologies to deliver a broad array of solutions that enhance knowledge and academic performance (Gibbons \& Fairweather, 2000; Rosenberg, 2001; Ruiz, Mintzer \& Leipzig, 2006). Recent innovations within the information and communication technologies field have assisted in defining the parameters for pedagogical strategies used in e-learning and in other forms of distance learning (Dabbagh \& Bannan-Ritland, 2005). However, large class size, entrenched faculty, and ICT limitations across the eight medical universities, challenges the systemic and comprehensive changes that the project envisions.

Although broadly constructivist in its theoretical foundations, the project's conceptualisation for e-learning is based in part on empirical research from behaviourism, cognitive, and situational theories. Guided by learning theories advanced by Dewey (1916), Piaget (1972), Vygotsky (1978) and Bruner (1990), constructivism is defined as active construction of new knowledge based on a learner's prior experience. Evolving from this eclectic model of learning is the specification of pedagogical methodologies and strategies that direct responsibility for the instructional sequence to learners and encourages the learner with creating, collaborating, and constructing new knowledge. The application of constructivism to an e-learning theoretical approach has also been supported by research (Egbert \& Thomas, 2001; Hung, 2010; Koohang, 2009; Randall, 2001). Constructivist learning theory supports knowledge construction applied to e-learning by encouraging a learner-centred focus as well as collaboration among learners. Koohang and Harman (2005) stated that e-learning is the delivery of instruction through various electronic media where designs include learning theories and principles consistent with a constructivist approach. E-learning instructional design has relied on instructional models including behaviourism, cognitive, humanism, and constructivism (Lee \& Lin, 2009).

Koohang (2009) advanced a model based on constructivism learning theory within elearning environments. The model includes three categories for elements of constructivism represented in the design of learning activities, learning assessment, and instructor's roles. The design of e-learning activities includes collaboration, cooperation, multiple perspectives, real world examples, scaffolding, self-reflection, multiple representations of ideas, and social negotiation which support a learnercentred approach. The learning assessment elements consisted of instructor assessment, curriculum assessment, and self-assessment while the instructor's roles include coaching, guiding, mentoring, acknowledging, providing feedback, and assessing student learning. The application of Koohang's model has direct application to the systemic change envisioned by the project (McCombs, 2004; Lee \& Lin, 2009).

The learner-centred approach, consistent with constructivist principles, provides a foundation for transforming education facilitated by the potential impact and influence of technology. Technology can be used to change the role of teachers to that of colearners and contributors to the social and interpersonal development of students, counterbalancing the potential of ICT to create personal and social isolation and alienation (Cook, 2005; McCombs \& Vakili, 2005). E-learning use by medical educators to improve the efficiency and effectiveness of educational interventions also recognises the social, scientific, and pedagogical challenges (Ally, 2008). Online delivery of education can then provide a means to centralise course development and link multicampus learners to academic instructors on a national and international scale. A 
learner-centered e-classroom is not only dependent upon technology but also dependent upon political, organisational, cultural, and philosophical factors (Dede, 2002). As changes to the definition of "schooling" occur, especially within medical education, the possibilities afforded by e-learning will be enhanced or diminished, dependent upon these and other factors (Ruiz et al., 2006).

Instructional strategies that encompass the characteristics of pedagogical models grounded in constructivist as well as learner-centred views include: (a) promoting or supporting authentic learning activities; (b) facilitating problem solving, exploration, and hypothesis generation; (c) promoting collaboration and social negotiation; (d) supporting or facilitating role-playing activities; (e) promoting articulation and reflection; (f) supporting multiple perspectives; (g) supporting modeling and explaining; and (h) providing scaffolding (McLoughlin \& Oliver, 1999). Overall, the goal of these instructional strategies is to create a learning culture where collaboration, learning with self-awareness, multiple perspectives, and self-management are promoted, and where the role of the teacher is reciprocal, supportive, and communicative as it is responsive to learner needs This premise underscores the intent of the project and the development of a comprehensive e-learning, learner-centred approach to medical education. Given the constructivist foundation of the project as well as its transformation to a more learner-centred approach to the teaching-learning process, the design for the development of the Center of Excellence in E-learning requires support of the basic principles of constructivism and the strategies used in learnercentred education. E-learning development at the universities should include methods and instructional strategies that support the construction of knowledge which will enable opportunities for instructors and students to access the wealth of information and knowledge available through appropriate use of ICT and pedagogies (McLoughlin \& Oliver, 1999; Koohan, 2009).

\section{Purpose of the project}

\section{Centres of excellence in human resource health services}

The Vietnam Ministry of Health $(\mathrm{MOH})$ in collaboration with the Royal Netherland Embassy (RNE) in Hanoi have designed an innovative and creative model for improving and sustaining the capacity of Vietnam's medical universities to address the significant health issues of the country ( $Y$. Nguyen, personal communication 4 December 2007). As an integral part of a broader MOH and RNE initiative on human resource development for improved health and medical services, the project provides technical and consultative assistance in select medical and scientific components that are currently served by international personnel and other resources. As a result of this project as well as other projects in the country, the preparation of medical personnel will become more cooperative and broad-based in addressing medical and health needs of the country. In addition, the project will provide the foundation by which continued growth and the sustainability are encouraged.

Centres of Excellence (COEs) were identified and are viewed as one means to assist in accomplishing the project's objectives. Medical units and universities must collaborate as partners to address increased public health concerns and related issues. Centres of excellence are based on a collaborative model capable of coalescing common requirements and addressing infrastructure inefficiencies and ineffectiveness from a holistic, medical perspective. Creating a sustainable, successful COE challenges 
traditional command and control thinking (Chang, 2010). Stakeholders must collaborate on cross-disciplinary initiatives. To meet this goal, the COE must be built upon a collaborative, versus traditional command and control, governance structure. The following outlines key COE functions and deliverables:

- Enable collaboration across universities to ensure consistency and integration.

- Provide a governance framework that enables open participation from each stakeholder and/or medical unit.

- Establish modeling designs, related technologies and a methodology to enable collaborative modeling.

- Create a focal point where strategy can be translated into operational reality.

COEs will provide a level of program outcomes that are projected to assist Vietnam's tertiary medical personnel preparation programs in developing more self-sufficiency in addressing postgraduate training and research. Centres of excellence will enable inter-university cooperation and collaborative necessary effect change. COEs provide leadership, expertise, and resources to enable faculty and students to become selfdirected in their teaching and learning (Churton, 2008). Five medical and scientific constructs were identified for COE development. COEs should serve five basic needs:

- Support: For their area of focus. This may be through services needed or providing subject matter experts.

- Guidance: Standards, methodologies, tools and knowledge repositories are typical approaches to filling this need.

- Shared learning: Training and certifications, skill assessments, team building and formalised roles are all ways to encourage shared learning.

- Measurements: COEs should be able to demonstrate they are delivering the valued results that justified their creation through the use of measurable outcomes.

- Governance: Allocating limited resources (money, people, etc.) across all their possible use is an important function of COEs (Kagan, 1994).

Although five centres of excellence are proposed, the purpose of this article is to address the design and development of the Centres of Excellence in e-Learning as integral parts of the COEs network and a means to transition the application of ICT and elearning to the professional preparation of medical doctors and health specialists in Vietnam.

\section{Methods}

\section{Participants and design}

To collaboratively address the pressing higher education concerns of the country, eight medical universities were selected to participate in the project (Y. Nguyen, personal communication, March 2008). The consortium of universities included Hanoi Medical University, Hue University, Tay Nguyen University, Ho Chi Minh City Medicine and Pharmacy University, Can Tho Medical University, Thai Nguyen University, Hai Phong Medicine University and Thai Binh University of Medicine. Tay Nguyen Medical University also participates to a limited degree for the express purpose of building capacity in core construct areas. In addition, the Learning Resource Center at Hue University was also included. The universities are geographically dispersed across Vietnam including programs in rural and urban settings. 
A qualitative design was used to ascertain critical medical and scientific components identifying pressing concerns for university training and research. A series of centralised and outreach meetings were conducted to identify medical and health components most critical for the country and for each respective university program. Consortium representatives, including university administrators, instructors, staff and resource personnel, were organised into five teams representing each of the designated health components. National medical and health concerns identified by the teams included: medical education, research, management, economic evaluation, and elearning. Within each component area, sub-components were also identified to enable a more concentrated and comprehensive effort to meet intended outcomes. As a result, five centres of excellence were planned, based upon the medical and scientific components derived from the collaborative and qualitative design process.

Centres of excellence were considered for development at participating universities and also the Learning Resource Center (LRC), a support unit at Hue University. The number and categories of COEs at each medical university were determined based upon university capabilities, institutional capacity, and commitment to the proposed COE outcomes. Additional criteria included competence of team members in the selected components, market needs, and the support and commitment of the respective university administration ( $Y$. Nguyen, personal communication, March 2008). Membership of each COE varied depending upon the medical and/or scientific component. Approximately 2-3 members from each university were assigned to the medical education, economic, research, and management COEs. COE membership was determined through application and recommendations from each university administration. COE members received additional compensation as well as traveling expenses as an incentive for their participation. The COEs for e-learning were comprised of 1 or 2 members per university.

\section{Centres of Excellence in e-Learning}

The focus of the COEs is to develop expertise and resources in the identified medical and/or scientific component areas. COE sustainability is measured in part by the capacity in which the COE provides the necessary leadership within each respective university as well as providing consultative services to other universities. As originally proposed, COEs were anticipated to develop a cadre of expertise competent to provide consultative services to other universities. Consultative and support services would consist of training, evaluation, and other assistive activities in the areas of medical economics, research, management, and medical education and e-learning. Further, COEs activities were planned throughout the year with a culminating annual progress or status meeting. The annual meeting intended to evaluate the progress of the COEs during the previous year and to plan for the succeeding year.

As a result of the group planning and analysis process conducted, two centres of excellence in e-learning were identified. Hanoi Medical University (COE-HMU) and the Learning Resource Center at Hue University (COE-LRC) were designated for the leadership in e-learning. E-learning for the purpose of the COEs was broadly defined to include electronic teaching-learning, online course management programs, blended or hybrid applications, video conferencing, as well as the use of DVD and other multimedia strategies. 


\section{Hanoi Medical University (COE-HMU)}

Hanoi Medical University (HMU) was founded in 1902 and is considered the premier medical university in Vietnam (HMU, n.d.). The university has approximately 2,500 undergraduate students and over 3,000 postgraduate students. Approximately 800 undergraduates and 900 postgraduate students are enrolled each year. Approximately 170 instructors hold terminal degrees. HMU is academically organised across several faculties (colleges) and departments addressing a broad range of medical education and research. The departments of surgery, pediatrics, psychiatry, medical, education and public health were targeted for initial developments in e-learning (Le Ngoc, 2009).

The secretariat for the COEs is based at Hanoi Medical University. The COE in elearning at Hanoi Medical University (COE-HMU) serves as the coordinating and / or administrative unit in e-learning for the other seven universities. Management of the $\mathrm{COE}-\mathrm{HMU}$ is directed by two co-coordinators. One co-coordinator is an information technology expert and also serves as the HMU IT manager. She is assisted by a staff comprised of information and communication technology specialists as well as academic content specialists. The other co-coordinator is a faculty member in public health. Her expertise lies in the application of content and pedagogical instruction to an e-learning environment. The rationale for the designation of two coordinators was to integrate information technology with sound pedagogical applications. Churton (2004) suggested that the integration of academic content with ICT is critical since instructors, especially in the medical fields, are often more attentive to a colleague with expertise in similar content areas as well as in instructional technology. Given the newness of e-learning for medical instructors, this relationship with a colleague who can demonstrate the product is important.

The COE-HMU staff perform a multitude of responsibilities, some directly related to the COE and others reflecting a continuation of daily responsibilities associated with university employment. First, the COE is responsible for the infrastructure at HMU including ICT installation and maintenance necessary for the development of the elearning program. Duties require significant expertise, planning and oversight to ensure that e-learning technologies, including software, hardware, and Internet viability, are available and sustained for successful e-learning applications. At HMU, a teaching-demonstration computer laboratory was designed with 30 plus units in addition to a video conferencing codec and LCD projector. All technical assistance including hardware/software installation, training, and maintenance of servers, Internet access and bandwidth, including electronic mail and communications, fall within the purview of the COE-HMU in e-learning.

Second, the COE-HMU is responsible for the training necessary to transition HMU instructors from traditional lecture, teacher-directed methodologies and practices, to an e-learning, student-focused teaching environment. Transition includes understanding the strategies and technical aspects of the course management software, ICT for the classroom, and other multimedia activities supporting e-learning, technically as well as pedagogically. Instructor training consists of formal presentations as well as individual consultations. The e-learning units at the other six universities consist of 1 or 2 people, usually ICT personnel, while the COE-HMU and the COE-LRC have several support personnel within the unit. 
Third, COE staff is responsible for meeting the continuing ICT needs of the university. The HMU ICT unit is required to upgrade and complete the Internet services network for the university in order to maintain sufficient capacity for implementing e-learning. Although the COE e-learning system is integrated with the university's ICT infrastructure, the increased responsibilities, time and effort, and management work necessary to maintain a viable ICT system for the entire university places a significant strain on a new and developing COE. Overlapping ICT responsibilities with limited staff may seem cost and time effective initially, but in reality the opposite is often proven more realistic and long term success is not difficult to achieve.

\section{COE-Learning Resource Center at Hue University (COE-LRC)}

In addition to the COE-HMU, a second COE for e-learning was identified at Hue University's Learning Resource Center (COE-LRC). Hue University was established in 1957 and is a multi-disciplinary and multi-discipline university including Colleges of Education, Sciences, Medicine and Pharmacy, Agriculture and Forestry, Arts, Economics, Foreign Languages and Faculties of Physical Education, and Hospitality and Tourism (HU, n.d.). Hue University's diversity in its broad academic approach is unique compared to the other seven universities involved in the project. However, for the purpose of the project, the medical college was the only college participating but the opportunity for involvement by the other colleges was enhanced.

The Hue University Learning Resource Center (LRC) is housed in a modern fourstorey facility providing advanced education resources and online teaching-learning programs, opened in 2004 (LRC, n.d.). The LRC contains over 500 PC workstations, 2 computer laboratories, training-conference centre audiovisual equipment including 2 viewing rooms, 14 printers (network printing), and 9 photocopiers. The LRC also lists over 65,000 monograph copies (9,000 titles), 4,500 reference copies (4,000 titles), 500 periodical titles, 1,500 audiovisual items (900 titles), and several international edatabases. The LRC staff consists of librarians, computer programmers and technicians, graphics and multimedia personnel.

The rationale for the addition of a second COE in e-learning was due to established expertise and resources at HUE-LRC. There are only four centres like the Hue-LRC based at Vietnam's universities. The HUE-LRC e-learning unit is directed by a medical faculty instructor and assisted by an instructional and design support unit. The director also manages the LRC. Similar to the COE-HMU, responsibilities for developing e-learning were added to the staff's ongoing duties. Consistent with an elearning teaching-learning philosophy, the LRC promotes open access to collections, use of electronic resources, student self-directed use of information and data research services, integration of resources with academic programs, and the involvement of academic staff in LRC resource and training activities (LRC, n.d.).

\section{E-learning needs assessment}

The eight medical universities were surveyed using a needs assessment which intended to establish a baseline representing the e-learning status of each program. In addition, the selection of the learning management system (LMS) holds significance for instructional transition as well as for identifying specific responsibilities for the $\mathrm{COE}$ support teams. A comprehensive needs assessment was designed and administered in the spring of 2008 to ascertain the level of e-learning knowledge and capacity existing 
at each university. The needs assessment addressed four broad constructs relating to the development and application of e-learning programs including: (1) e-learning system support and development which addressed current e-learning status, evaluation, instructor support, philosophical position, and funding; (2) e-learning students includes ICT knowledge base of students, technical support, planned orientations, and student training; (3) course design and structure, including type of elearning class, LMS selection, anticipated document and file types, evaluation of students and instructors; and (4) pedagogical implications for e-learning, including questions addressing instructors' e-learning expertise, instructional strategies and methods, content originators and experts, and management and communication (Churton, 2008). Six out of the eight universities returned the survey and of the surveys returned only two were complete.

Results of the needs assessment and an on-site visitation demonstrated that each university is unique and envisions a broad and at times unclear interpretation of elearning needs. Due to the initial development of the programs, e-learning needs and current status were based primarily upon existing expertise and resources. It must be noted that the surveys were completed by one person from each university reporting the needs, and this may not be representative of the general e-learning status at each university. In addition, other than COE-HMU and COE-LRC, university e-learning units consisted of one or two individuals, also tending to include an individual who was also the ICT manager. Ho Chi Minh City Medical and Pharmaceutical University offered a unique e-learning structure, reporting that each faculty or college designed and developed their own e-learning system. A university-wide model was not established which could prove to be, over time, too expensive and confusing to sustain (Moore, 2009). The measurable difference between a university's existing ICT elearning capacity and their long term goals was significant in most cases and perhaps unobtainable given a multitude of philosophic, economic and pragmatic factors.

\section{Learning management system (LMS) selection}

The LMS Moodle (http://moodle.org/; Cole \& Foster, 2008) was selected to be used system wide. The primary rationale was attributed directly to licensing costs and that COE-HMU and COE-LRC had already downloaded the software and implemented training. Being an open source product, Moodle involves no initial or ongoing fees in the downloading or utilisation of the software. In addition, online support and training is available in most cases without additional fees. Third-party manuals and resources are available for a nominal fee in many instances. The COE-HMU supported training for all university e-learning members in the software application and in instructional aspects of Moodle. Although limitations are associated with Moodle, in hindsight, it seems to have been a practical decision to begin the transitional process of developing e-learning programs.

\section{COE e-learning development and enhancement activities}

Given the four years of the project, there has occurred a wide-variety of e-learning development within the two COEs as well as at the other six universities. The annual conference dialogs as well as annual progress clearly demonstrate the need for continued training and development. It is prudent to report each COE separately due to the baseline from which each unit began its operation. The project initially cited one COE in e-learning. However, due to the level of expertise at HMC-LRC, a second COE was designated. 


\section{COE-Hanoi Medical University}

It should be noted that HMU prior to the development of the COE in e-learning offered only limited experiences and/or activities in e-learning. Although the use of multimedia was present in some classes, a university wide initiative did not exist. The COE project enabled Hanoi Medical University to improve the university's information and communication technologies, the library system and the local area network. Further, HMU was equipping departments with computers, averaging 1 or 2 computers per unit, although instructors tended to purchase their own computers. In addition, the university provided computer laboratories and Internet access to students in their courses. Few students own personal computers.

The goal of the COE-HMU was to design a unit to serve as an e-learning resource for HMU as well as other medical schools, health institutions and services in the country. Objectives included:

- Administrative procedures, employment of staff, and organisational structure and procedures for program implementation completed within six months.

- Completion and upgrade of the HMU infrastructure and LAN network capacity at Hanoi Medical University to sustain e-learning applications.

- E-learning orientation and awareness sessions at HMU and other medical schools through workshops, seminars, and conferences.

- Short-term training to address specific needs of e-learning with support from local and national experts.

- After two years, a training group of 15-20 instructors in HMU who can plan, develop and use e-learning.

- By the end of the project, a core group of e-learning experts in e-learning who can provide training to other medical schools and health institutions.

From the start of the project, COE-HMU has undergone significant change relative to their e-learning program. The HMU-COE has conducted workshops and training programs designed to increase the e-learning competencies of instructors at HMU. A series of training programs were conducted addressing e-learning course design, pedagogy, and course evaluation from a constructivist and learner-centred view including:

- E-learning basics and considerations for online teaching

- Creating an online course shell with Moodle

- Planning for e-learning programs

- Transitioning course content to e-learning

- Curriculum development and e-learning course design

- Considering multimedia content

- Learning content online

- Content vs. pedagogy

- Moodle: Pedagogical tools/strategies

- Moodle: Introduction: Open source learning or course management system

- Course design-management

- Online course evaluation

Although a variety of e-learning training and course development workshops have been conducted, the application of this knowledge to increase the number of e-learning courses has been limited. Of the courses reviewed to date, few if any have surpassed 
the "development" stage. The process has been one of attempting to transfer traditional face to face teaching strategies to an e-learning environment and/or to a DVD module. Text (lecture notes) with limited graphics seems to be the common approach which diminshes the effectiveness and opportunities associated with elearning.

Several factors have played a role in the progress to date. First and foremost, as cited previously, the COE-HMU staff carry responsibilities for other ICT aspects of the university. Time and time management certainly affect productivity. The instructors' time commitment was limited, in relation to transitioning from traditional classroom instruction to a design that uses the pedagogical aspects of e-learning, either in total or through a blended approach. Further, offering short-term workshops and seminars to change teaching-learning behaviour is inadequate. Extended training under instructor supervision via group participation as well as direct instruction on an individual basis is more productive (Scagnoli et al., 2009). In addition, the university, if truly dedicated to e-learning and to the objectives of the project, should release the COE-HMU staff from university duties so that the staff can concentrate entirely on the e-learning development at HMU.

\section{COE-Learning Resource Center (LRC)}

Unlike the COE-HMU, the Learning Resource Center at Hue University was already established and in operation for several years prior to the start of the project. Library resources and ICT staff were instituted and to some degree already assisting university faculty in the development of multimedia and e-learning applications. Moodle had been installed and ICT personnel trained. This foundation provided the COE-LRC with the necessary technological infrastructure, hardware, and expertise necessary to initiate a concerted plan and procedures for enhancing e-learning at Hue University. An initial stage of development was for the COE-LRC to conduct a 30 day training program to introduce, develop, and assist university instructors and LRC staff into e-learning and the transition from traditional, teacher-directed formats to a more student-directed approach using e-learning. The format consisted of an initial three-day open dialogue on the advantages and limitations of using e-learning to deliver university courses. University e-learning culture, pedagogical design, and the differences in teaching online (Allen \& Seaman, 2008) as opposed to teaching in a traditional face to face classroom environment were presented and included:

- Dialogue on the transition to an e-learning university model

- E-learning challenges and implications.

- Developing an e-learning university culture

- E-learning and ICT structure

- Course management, instructor management, and student management

- Administrative support and sustaining and expanding a university e-learning model

The remainder of the training program focused on the design, development and application of an e-learning course using Moodle. All participants created and designed, to varying degrees, an online course or program. Faculty from the College of Medicine focused on the classes they were teaching while LRC personnel were assigned one of several project areas including student and instructor e-learning orientations and specific online training using Moodle. The four week program 
addressed the following broad constructs as well as specific aspects of designing elearning activities using Moodle:

\section{Management and sustainability of e-learning classes}

- Orientation to e-learning courses vs. traditional courses

- Accessing university servers, security issues, and login to the LMS

- Navigation within the LMS

- Creating a new course account shell in the LMS

- Enrollment/ deletion/ modification to online class members

- Creating effective announcements and notices

- Creating faculty and student homepages

- Creating online course/ class materials

- Uploading and modifying e-course content

Pedagogical implications of online learning

- Designing course information for LMS applications

- Utilisation of communication options such as email, listservs, etc

- Presenting and accessing resources and academic content

- Strategies for providing online forums/ real-time virtual classroom and chat

- Collecting and annotating Internet-based curricular resources

- Creating online assessments, assignment submissions, file management

- Creating teacher informational and student homepages

- Utilising grade book/statistics with student access

- Creating a self-management system for teaching online

The outcomes of this concentrated training, which did not occur at COE-HMU, was indepth training of 10 university instructors with a significant foundation for understanding and designing basic e-learning courses. Although further development would be required, a basic level of understanding of transitional requirements was attained, including management aspects of the LMS as well as pedagogical considerations necessary for an effective e-learning course design. In addition, the LRC staff assigned to the e-learning support unit also developed consultative skills necessary to assist instructors in their e-learning development.

Further, the COE-LRC designed and published several manuals on the process and application of e-learning, based upon the training that was conducted. These manuals were disseminated to instructors at Hue and also to other COE members. Several additional training sessions occurred on an annual and bi-annual basis. Topical areas included pedagogical implications for e-learning as well as converting content to an elearning format. Further, the COE-LRC enrolled staff members in an Australian program for designing DVDs and multimedia. Staff were also sent to Singapore for further training in the application of the LMS for specific learning outcomes and delivery strategies.

The COE-LRC also conducted online course development at two COE universities. The COE-LRC selected three people to undergo extensive e-learning course evaluation. A matrix was developed based upon Moodle applications. The team evaluated courses at Tai Nguyen University to assist in their e-learning development. The unit also conducted student focus groups in researching e-learning needs of students. These sessions included university instructors and provided critical information to be considered in course design and development. 


\section{Discussions}

The project for the development of centres of excellence in e-learning has completed its fourth year. Whilst the Vietnam Ministry of Health in collaboration with the Netherlands Government proposed using centres of excellence to address higher education needs of the country's eight medical universities, the tasks of developing five functional and viable centres of excellence were quite ambitious. The development of centres of excellence was seen as a viable approach to assist in resolving limited expertise and resources in several key medical and scientific areas including medical education, economics, management, medical research and e-learning consistent with a concerted approach to design a more learner-centred approach to medical personnel preparation. Further, the centres of excellence in e-learning at Hanoi Medical University and Hue University Learning Resource Center initiated the process of not only transitioning university instructors and students to e-learning but also of enhancing the ICT infrastructure necessary to sustain a viable e-learning environment. Unlike the other COEs, this dual responsibility as well as the responsibility to enhance the e-learning capabilities of the other COEs, was at best highly aspirational. With one year remaining for further enhancement, much has been learned from the preceding years that will assist in year five, as well as offer considerations by other programs interested in reformation.

COE-HMU and COE-LRC have accomplished several objectives in meeting the elearning needs of their respective programs. However, both programs have struggled with several aspects of implementing the COE. As previously stated, COE-HMU was created from a baseline of limited e-learning activity and facilities. Although the basic ICT infrastructure at HMU was present, the unit's physical location, network servers, and teaching laboratory were not centralised, being dispersed across campus. Although the basic structure of a teaching laboratory was present, it could not be considered a state-of-the art e-learning environment. In addition, considerable time and finances were dedicated to upgrade the ICT network in order to sustain e-learning applications. The COE-LRC on the other hand, had previously implemented e-learning activities prior to the start of the project, and provided a state of the arts e-learning facility. A primary objective for both programs was to begin the process of learnercentred education supporting a constructivist approach to teaching-learning. Koohang's (2009) model on constructivism learning theory in e-learning environments included three categories: the design of learning activities, learning assessment, and instructor's roles. The two COEs conducted a variety of short-term e-learning activities for instructors and to a lesser extent for university students, assessment and evaluation of course and learning activities, and identification of the roles and functions of a medical university instructor in an e-learning environment.

Both COEs increased their e-learning through professional and staff development and e-learning services obtained from external consultations. Although instructors were afforded training and consultation, the implementation of learner-centred e-learning courses was not successful with respect to the use of authentic learning activities, problem solving, collaboration and social interaction, reflection and other strategies as recommended by McLoughlin and Oliver (1999). In evaluating e-learning courses that were developed at both programs, it was clear that the primary instructional philosophy remained focused on traditional, lecture-centred formats. Although some instructors offered evidence that a learner-centred constructivist model was being considered, for the most part e-learning courses in various stages of development were 
more representative of instructor's lecture notes posted to the learning management system with a limited utilisation of illustrations and graphics. Entrenched instructors using traditional, lecture-centred approaches to teaching remained for the most part, adamant in their philosophy and approaches to medical education. The process of instructional and philosophical transformation is difficult process irrespective of university or country. Concentrated and sustained training sessions which consistently reinforced strategies and practices grounded in learner-centred and constructivist principles is required (Allen \& Seaman, 2008).

What has been experienced at both COEs is not unlike transformations occurring at other universities. Systemic change processes are difficult and may be confounded, as in this case, with the added dimension of responsibility for incorporating e-learning design, strategies, and methods in their instructional practices. In addition, students must undergo a transformative change in their learning approach as well. The process of transformation creates transformative learners; those who are increasingly able to modify their frame of reference, examine assumptions, expectations, values, attitudes, and accept varying viewpoints. Transformative learning (Cranton, 2009) is less about how the educator teaches and more about how the educator thinks about teaching and learning. To foster transformative learning, the instructor must support critical reflection and questioning among the learners. This has not been the trend in the COEs.

Medical instructors are responsible for effectively communicating content within their area of expertise. It is the responsibility of the COE to assist instructors and learners to teach-learn differently. Dependent learners prefer direct instruction and being told exactly what to do and when to do it. This has been the traditional practice in the medical schools of Vietnam. In contrast, self-directed learners prefer self-directed project work, discovery learning, and student-directed discourse. Self-directedness transfers to learner responsibilities for their education (Frohberg et al., 2009). The outcome for education is to produce empowered, thinking people who participate in their own learning. This is especially true for medical personnel and one that is difficult to achieve given the historical transformation of traditional teaching-learning methodologies found in Vietnam's medical universities. To assist in accomplishing this end, the COEs should consist of individuals who support and can influence medical personnel and students in this process. For systemic change to occur, COEs must be in the position to exert influence over entrenched instructors, administrators and other individuals who guide the curriculum.

Part of the frustration in meeting the purpose and objectives of the COE is not having a competent support unit whose sole responsibility is dedicated to increasing e-learning. Centres of excellence and/or e-learning support units are perhaps one of the most critical components in designing effective e-learning programs. To be successful, support units or COEs must be designed and developed with an expressed mission to focus on e-learning. Dispersing a unit's resources to other responsibilities hinders the sustaining of initial and/or long term growth. Staff assigned to the COE must be full time with responsibilities dedicated to the e-learning unit. COEs require personnel with e-learning expertise including knowledge in LMS, graphic design, animation, multimedia, and perhaps most importantly, pedagogical skills and strategies. Effectiveness demands more than ICT knowledge or knowledge concerning the LMS. Too often, a support unit in e-learning is directed by ICT personnel. Although proficient in ICT skills, applications, and software functions; and perhaps the general 
knowledge of the pedagogical strategies used; expertise in teaching and the use of learner-centred strategies may not be evident. Leadership should be provided by a seasoned pedagogical specialist versed in e-learning instructional practices. This represents intrusion into a culture that has been historically solidified in its instructional approaches.

An e-learning culture is a sustainable community of learning consisting of collaborative and shared interests supported and/or mediated through technology and guided by well formulated practices and protocols for designing, developing, teaching, and evaluating e-learning programs. Collaborative interests on campus include professors, students, administrators, libraries, and the support personnel and unit. Figure 1 depicts the various components included within a supportive e-learning university culture.

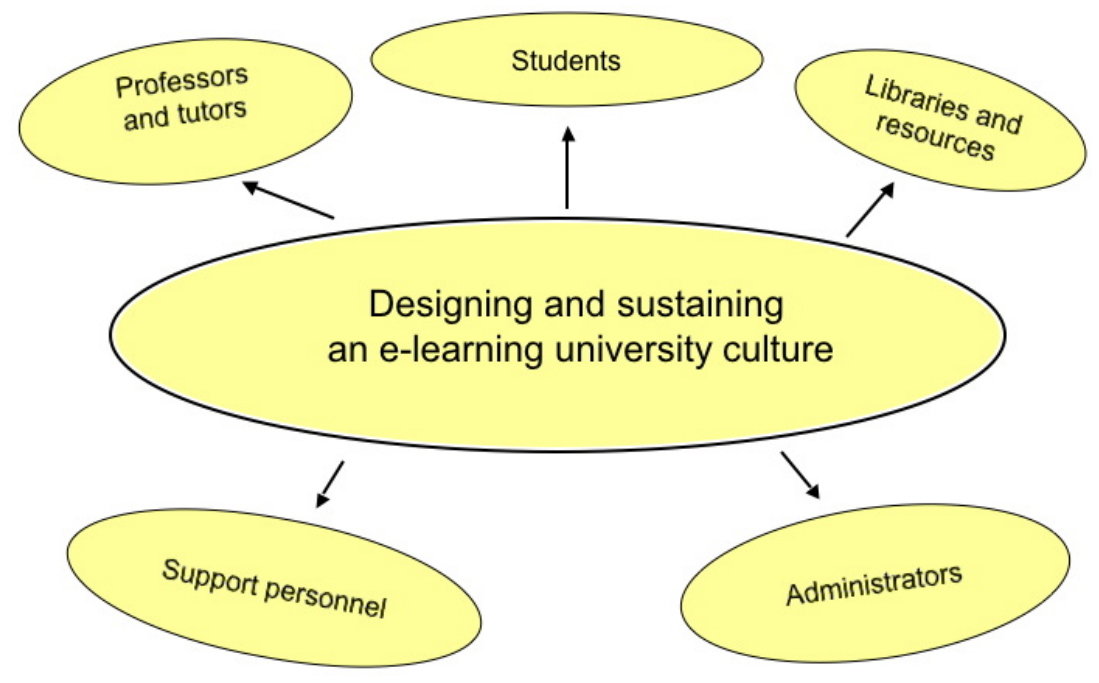

Figure 1: E-learning culture (Churton, 2008)

To be successful, the culture of e-learning must be developed holistically (Churton, 2008). Due to considerable costs and time investment, individuals or single faculties will not sustain an effective e-learning program. What has been learned is that considered time is required to not only initiate an effective e-learning program but to sustain one as well. The culture requires that universities dedicate a support unit or COE that addresses the e-learning needs of instructors, students, and administrators. Effective COEs ensure that:

- Instructors and learners have effective e-learning support systems managed by expertise in e-learning and the dedicated time to design programs.

- E-learning course designs are consistent with outcomes, objectives are measurable, and the delivery systems facilitate learning outcomes.

- Instructors receive extended training in course design, development, pedagogy, and evaluation.

- Faculty are evaluated as to their e-learning teaching effectiveness and provided feedback. 
- Evaluations are used to provide systematic and ongoing data for use in course improvement?

- E-learning missions are consistent with university goals and that needs have been comprehensively determined.

- University administrators are financially committed to quality, professional development and resources in e-learning applications.

Sustainability of effective e-learning programs is difficult to initiate and maintain. Due to the relatively limited time, personnel, physical resources and infrastructure for the COEs, it is understandable that the culture across the university, or at least with the select faculties, has not had the extended time required to fully develop the scope and functioning of their centres. COEs, if designed and managed appropriately, can assist in developing as well as maintaining e-learning programs. Considerable time and financial investments are required to ensure that effective instruction in academic content is realised. Both programs are in need of exemplary e-learning course models to demonstrate effectiveness and transformation. Identifying a select few (2-3) instructors with release from day to day responsibilities to focus specifically on elearning might better serve the process for long term development. The COEs at HMU and LRC, although continuing to be developmental in nature, have at least initiated the extended process of addressing the e-learning needs of their respective universities.

\section{References}

Allen, E. \& Seaman, J. (2008). Staying the course: Online education in the United States, 2011. http: / / sloanconsortium.org/publications/survey/survey05.asp [viewed 23 Aug 2011].

Ally, M. (2008). Chapter 1: Foundations of educational theory for online learning. In T. Anderson (Ed.), The theory and practice of online learning (2nd edition, pp. 33-60). Edmonton, AB: AU Press, Athabasca University. http:/ / cde.athabascau.ca/online_book/

Bruner, J. (1990). Acts of meaning. Cambridge, MA: Harvard University Press.

Chang, C. K. (2010). Acceptability of an asynchronous learning forum on mobile devices. Behaviour and Information Technology, 29(1), 23-33. http: / / dx.doi.org/10.1080/01449290701806337

Churton, M. (2004). Transitioning to e-learning: Pedagogical and support considerations. Chinese Journal of Distance Education, 1(2), 219-238. http: / / en.cnki.com.cn/Article_en/CJFDTOTALDDJY200409013.htm

Churton, M. (2008). Center of Excellence 2007-2008 Final Report. Unpublished manuscript.

Churton, M. (2010). Center of Excellence 2009-2010 Final Report. Unpublished manuscript.

Clark, D. (2002). Psychological myths in e-learning. Medical Teacher, 24(6), 598-604. http: / / dx.doi.org/10.1080/0142159021000063916

Cole, J. \& Foster, H. (2008). Using Moodle (2nd edition). Sebastopol, CA: O’Reilly Media Inc. http:/ / shop.oreilly.com/product/9780596529185.do

Cook, D. A. (2005). The research we still are not doing: An agenda for the study of computerbased learning. Academic Medicine, 80(6), 541-548. http:/ / journals.lww.com/academicmedici ne/Fulltext/2005/06000/The_Research_We_Still_Are_Not_Doing_An_Agenda_for.5.aspx

Cranton, P. (2009). Understanding and promoting transformative learning: A guide for educators of adults. Hoboken, NJ: Wiley. 
Dabbagh, N. \& Bannan-Ritland, B. (2005). Online learning: Concepts, strategies, and application. Upper Saddlebrook, NJ: Pearson, Merrill Prentice Hall.

Dede, C. (2002). Interactive media in an interview with Chris Dede. Syllabus, June, 12-14.

Dewey, J. (1916). How we think. Boston, MA: Houghton Mifflin Company.

Egbert, J. \& Thomas, M. (2001). The new frontier: A case study in applying instructional design for distance teacher education. Journal of Technology and Teacher Education, 9(3), 391-405. http: / / www.editlib.org/p/8374

Frohberg, D., Goth, C. \& Schwabe, G. (2009). Mobile learning projects: A critical analysis of the state of the art. Journal of Computer Assisted Learning, 25(4), 307-331. http: / / dx.doi.org/10.1111/j.1365-2729.2009.00315.x

Gibbons, A. \& Fairweather, P. (2000). Computer-based instruction. In S. Tobias \& J. Fletcher (Eds), Training \& retraining: A handbook for business, industry, government, and the military (pp. 410-442). New York: Macmillan.

HMU (n.d). Hanoi Medical University official website. http:/ / www.hmu.edu.vn/ [viewed 2 Jun 2009].

Hoat, L. H., Nguyen, M. S. \& Wright, E. P. (2008). Perceptions of graduating students from eight medical schools in Vietnam on acquisition of key skills identified by teachers. BMC Medical Education, 8(5), 1-10. http:/ / www.biomedcentral.com/1472-6920/8/5

Hoat, L. H. \& Wright, E. P. (2008). Community-university partnership: Key elements for improving field teaching in medical schools in Vietnam. Rural and Remote Health, 8(4), 894912. http:/ / www.rrh.org.au / articles / subviewnew.asp?ArticleID=894

HU (n.d.). Hue University official website. http:/ / www.hueuni.edu.vn/ [viewed 10 Jul 2011].

Hung, D. (2001). Design principles for web-based learning: Implications for Vygotskian thought. Educational Technology, 41(3), 33-41.

Kagan, S. (1994). Cooperative learning. San Clemente, CA: Kagan Publishing.

Koohang, A. (2009). A learner-centered model for blended learning design. International Journal of Innovation and Learning, 6(1), 76-91. http: / / dx.doi.org/10.1504/ IJIL.2009.021685

Koohang, A. \& Harman, K. (2005). Open source: A metaphor for e-learning. Informing Science: The International Journal of an Emerging Transdiscipline, 8, 75-86. http: / / inform.nu/ Articles/Vol8/v8p075-086Kooh.pdf [viewed 28 Oct 2011].

Le Ngoc, A. (2009). Hanoi Medical University. Presentation Interfaculty Conference (Hanoi Medical University, Hanoi, Vietnam, 19 March 2009).

Lee, J. \& Lin, L. (2009). Chapter V: Applying constructivism to online learning: A new instructional design map. In C. Payne (Ed.), Information technology and constructivism in higher education: Progressive learning frameworks (pp. 58-73). Hershey, PA: Information Science Reference.

Leung, W. C. (2002). Competency based medical training: Review. British Medical Journal, 325, 693-696. http: / / dx.doi.org/10.1136/ bmj.325.7366.693

LRC (n.d.). Hue University Learning Resource Center. http: / / www.lrchueuni.edu.vn/aboutE/about.htm [viewed 5 Aug 2011].

McCombs, B. L. (2004). The learner-centered psychological principles: A framework for balancing a focus on academic achievement with a focus on social and emotional learning needs. In J. E. Zins, R. E. Weissberg, M. C. Wang \& H. J. Walberg (Eds.), Building academic success on social and emotional learning: What does the research say? (pp. 23-39). New York: Teachers College Press. 
McCoombs, B. \& Vakili, D. (2005). A learner-centered framework for e-learning. Teachers College Record, 107(8), 1582-1600. http: / / www.tcrecord.org/ Content.asp?ContentID=12088

McLoughlin, C. \& Oliver, R. (1999). Pedagogic roles and dynamics in telematics environments. In M. Selinger \& J. Pearson (Eds.), Telematics in education: Trends and issues (pp. 32-50). Kidlington, Oxford: Pergamon.

Ministry of Health (2007). Vietnam's health care system: A macroeconomic perspective. Hanoi, Vietnam: Ministry of Education.

Moore, J. C. (2009). A synthesis of Sloan-C effective practices: December 2009. Journal of Asynchronous Learning Networks, 13(4), 17-23.

http:/ / sloanconsortium.org/sites/default/files/v13n4_moore_eps_1.pdf

Nair, B. \& Finucane, P. (2003). Reforming medical education to enhance the management of chronic disease. Medical Journal of Australia, 179(5), 257-259. http: / / www.mja.com.au/public/issues/179_05_010903/nai10275_fm.html

Piaget, J. (1972). The psychology of the child. New York: Basic Books.

Randall, B. (2001). Effective web design and core communication issues: The missing components in web-based distance education. Journal of Educational Multimedia and Hypermedia, 4, 357-367. http: / / www.editlib.org/p/8440

Ruiz, J., Mintzer, M. \& Leipzig, R. (2006). The impact of e-learning in medical education. Academic Medicine, 81(3), 207-212. http:/ / journals.lww.com/academicmedicine/Fulltext/ 2006/03000/The_Impact_of_E_Learning_in_Medical_Education.2.aspx

Rosenberg, M. (2001). E-learning: Strategies for delivering knowledge in the digital age. New York: McGraw-Hill, 2001.

Scagnoli, N. I., Buki, L. P. \& Johnson, S. D. (2009). The influence of online teaching on face-toface teaching practices. Journal of Asynchronous Learning Networks, 13(2), 27-35. http: / / sloanconsortium.org/sites/default/files/v13n2_scagnoli_1.pdf

Vygotsky, L. (1978). Mind in society. Cambridge, MA: Harvard University Press.

Wiesenberg, F. \& Stacey, E. (2005). Reflections on teaching and learning online: Quality program design, delivery and support issues from a cross-global perspective. Distance Education, 26(3), 385-404. http: / / dx.doi.org/10.1080/01587910500291496

World Health Organization (2010). Small steps and big goals: Two countries' experiences in achieving $M D G s 4$ E 5. [ viewed 15 Jul 2011].

http: / / www.wpro.who.int/media_centre/press_releases /pr_201012+21.htm

Author: Dr Michael W. Churton, Professor, Department of Special Education College of Education, University of South Florida, Tampa, FL 33620, USA

Email: mchurton@usf.edu

Web: http: / / www.coedu.usf.edu/main/departments/sped/Faculty/MChurton.html

Please cite as: Churton, M. W. (2011). Transforming Vietnam's medical education through e-learning. In Hong, K. S. \& Lai, K. W. (Eds), ICT for accessible, effective and efficient higher education: Experiences of Southeast Asia. Australasian Journal of Educational Technology, 27(Special issue, 8), 1437-1454.

http: / / www.ascilite.org.au/ajet/ajet27/ churton.html 